\title{
Correlation of the severity of chronic kidney disease with serum inflammation, osteoporosis and vitamin D deficiency
}

\author{
CEWEN LIU and HUI LI \\ Department of Nephrology, Union Hospital, Tongji Medical College, \\ Huazhong University of Science and Technology, Wuhan, Hubei 430022, P.R. China
}

Received April 16, 2018; Accepted October 15, 2018

DOI: $10.3892 /$ etm.2018.6916

\begin{abstract}
Correlation of the severity of chronic kidney disease (CKD) with serum inflammation, osteoporosis and vitamin $\mathrm{D}$ deficiency was investigated. A total of 78 patients suffering from CKD who presented to the Union Hospital from December 2015 to December 2017 were selected randomly and divided into three groups based on the severity of the disease. Comparisons of interleukin-6 (IL-6), C-reactive protein (CRP), tumor necrosis factor- $\alpha$ (TNF- $\alpha)$, indicators of osteoporosis [serum phosphate, serum calcium and bone mineral density (BMD)], content of $25(\mathrm{OH}) \mathrm{D}$, serum sodium, serum potassium and BUN were conducted among groups. The correlation of in vivo creatinine $(\mathrm{Cr})$ with $\mathrm{C}$-reactive protein (CRP), TNF- $\alpha$, BMD and vitamin D deficiency were analyzed. With the aggravation of illness, IL-6, CRP, TNF- $\alpha$, serum phosphate, serum sodium, serum potassium and blood urea nitrogen (BUN) were increased gradually, while serum calcium, BMD and vitamin D were decreased significantly $(\mathrm{P}<0.05)$. The content of $\mathrm{Cr}$ in patients suffering from osteoporosis was significantly higher than that in normal group $(\mathrm{P}<0.05)$. The $\mathrm{Cr}$ of patients in the group with abnormal CRP was significantly higher than that with normal CRP $(\mathrm{P}<0.05)$. Analysis showed that there is positive correlation between $\mathrm{Cr}$ and $\mathrm{CRP}(\mathrm{r}=0.6961, \mathrm{P}<0.001)$, as well as between $\mathrm{Cr}$ and TNF- $\alpha$ $(\mathrm{r}=0.8969, \mathrm{P}<0.001)$; and negative correlation between $\mathrm{Cr}$ and BMD ( $\mathrm{r}=0.5472, \mathrm{P}<0.001)$, and between $\mathrm{Cr}$ and 25(OH)D $(r=0.4733, P<0.001)$. The severity of CKD is correlated with serum inflammation, osteoporosis and vitamin $\mathrm{D}$ deficiency. The higher the severity of the illness, the worse the condition of osteoporosis will be.
\end{abstract}

Correspondence to: Dr Hui Li, Department of Nephrology, Union Hospital, Tongji Medical College, Huazhong University of Science and Technology, 1277 Jiefang Avenue, Wuhan, Hubei 430022, P.R. China

E-mail: z1233215209@163.com

Key words: chronic kidney disease, inflammation, osteoporosis, vitamin D deficiency

\section{Introduction}

Clinical statistics have shown that chronic kidney disease (CKD) ranks third in the world, in terms of incidence rate and number of infected individuals, next to cancer and heart diseases $(1,2)$. It is caused by interaction of several kinds of nephropathy, so patients with renal diseases may develop CKD if they don't receive timely diagnosis and treatment $(3,4)$. Clinical treatment can lead CKD in remission, but this disease may cause complications such as the frequent occurrence of inflammation, decrease in serum calcium, osteoporosis and vitamin $\mathrm{D}$ deficiency. Therefore, attention should be paid to the prevention of the above complications and finding the successful treatment in clinic (5-8). In this study, the correlation of CKD with inflammatory factors, osteoporosis and vitamin $\mathrm{D}$ deficiency were analyzed, providing the basis for the follow-up clinical treatment.

\section{Patients and methods}

General data. A total of 78 patients with CKD presented to the Union Hospital (Wuhan, China) from December 2015 to December 2017 were selected and divided into three groups according to the severity of the disease: CKD I-II stage group, CKD III-IV stage group and CKD V stage group. Among patients in CKD I-II stage group, there were 12 males and 13 females with body mass index (BMI) of $25.5 \pm 2.76 \mathrm{~kg} / \mathrm{m}^{2}$, height of $169.54 \pm 17.54 \mathrm{~cm}$ and average age of $58.43 \pm 5.65$ years. In CKD III-IV stage group, there were 14 males and 12 females with BMI of $24.9 \pm 3.09 \mathrm{~kg} / \mathrm{m}^{2}$, height of $170.01 \pm 17.09 \mathrm{~cm}$ and average age of $59.65 \pm 6.09$ years. In CKD V stage group, there were 12 males and 15 females with BMI of $25.2 \pm 2.76 \mathrm{~kg} / \mathrm{m}^{2}$, height of $167.76 \pm 16.43 \mathrm{~cm}$ and average age of $58.21 \pm 5.32$ years.

Inclusion criteria: patients who had good adherence and no mental diseases and whose main organs such as heart, liver and kidney were not injured.

Exclusion criteria: patients who recently had infection symptoms or were suffering from cancer or osteoporosis.

The study was approved by the Ethics Committee of the Union Hospital and informed consents were signed by the patients or the guardians. 
Table I. Comparison of the general data of patients among different groups.

\begin{tabular}{lccc}
\hline Index & CKD & CKD & CKD \\
& I-II stage & III-IV stage & V stage \\
\hline Age (years) & $58.43 \pm 5.65$ & $59.65 \pm 6.09$ & $58.21 \pm 5.32$ \\
Sex (male/female) & $12 / 13$ & $14 / 12$ & $12 / 15$ \\
BMI $\left(\mathrm{kg} / \mathrm{m}^{2}\right)$ & $25.5 \pm 2.76$ & $24.9 \pm 3.09$ & $25.2 \pm 2.76$ \\
Height $(\mathrm{cm})$ & $169.54 \pm 17.54$ & $170.01 \pm 17.09$ & $167.76 \pm 16.43$ \\
\hline
\end{tabular}

CKD, chronic kidney disease; BMD, body mass index.

Methods. Venous blood samples $(8 \mathrm{ml})$ were collected from all patients on an empty stomach. After leaving the samples to stand for $30 \mathrm{~min}$, serum was separated through centrifugation at $8,000 \mathrm{x} \mathrm{g}$ for $15 \mathrm{~min}$ at $4^{\circ} \mathrm{C}$. Inflammatory factors interleukin-6 (IL-6) and tumor necrosis factor- $\alpha$ (TNF- $\alpha$ ) were detected by enzyme-linked immunoassay. C-reactive protein (CRP) was measured by an auto-chemistry analyzer (SmartChem; Row2 Technologies, Inc., Parsippany, NJ, USA).

Indicators of osteoporosis: serum phosphate and serum calcium were both measured by an automatic biochemical analyzer (Mindray Bio-Medical Electronics Co., Ltd., Shenzhen, China). When serum albumin level of the patient was $<40 \mathrm{~g} / \mathrm{l}$, the corrected blood calcium level was calculated. Bone mineral density (BMD) was measured by a bone density meter (MetriScan; Alara, Inc., San Jose, CA, USA) (9).

Determination of 25(OH)D: vitamin D deficiency was defined as $25(\mathrm{OH}) \mathrm{D}$ was $<15 \mathrm{ng} / \mathrm{ml}$, and the detection of this factor was carried out by magnetic particle-based chemiluminescence (Roche Pharma AG, Grenzach-Wyhlen, Germany) (10). Determination of serum sodium and serum potassium: ion selective electrode method and the auto-chemistry analyzer were used. Serum creatinine (Cr): It was analyzed using the auto-chemistry analyzer after enzymatic assay. Blood urea nitrogen (BUN): it was determined by ultraviolet-glutamic acid dehydrogenase assay and analyzed by the auto-chemistry analyzer.

Statistical analysis. The statistical software, Statistical Product and Service Solutions (SPSS; SPSS, Inc., Chicago, IL, USA) 17.0, was used for the statistical analysis of the data. t-test was used for enumeration data which were expressed as mean \pm standard deviation (SD). ANOVA was used for comparison between multiple groups and the post hoc test was the Least Significant Difference test. Pearson's analysis was employed for correlation analysis between variables. $\mathrm{P}<0.05$ was considered to indicate a statistically significant difference.

\section{Results}

Comparison of general data of patients among different groups. It was found that there were no differences in age, sex, BMI and height of patients among the groups (Table I).

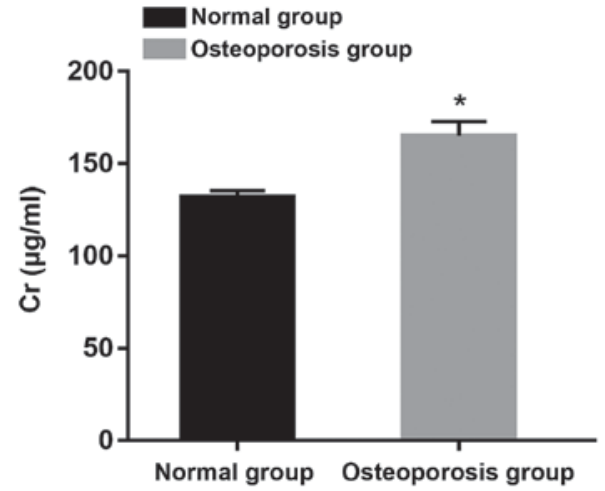

Figure 1. Comparison of $\mathrm{Cr}$ between normal and osteoporosis group. ${ }^{*} \mathrm{P}<0.05$. Cr, creatinine.

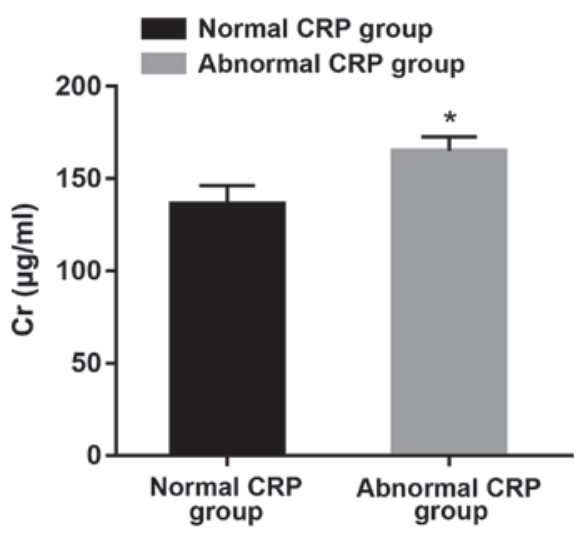

Figure 2. Comparison of $\mathrm{Cr}$ content between groups with normal and abnormal CRP. ${ }^{*} \mathrm{P}<0.05$. Cr, creatinine; CRP, C-reactive protein.

Comparisons of inflammatory factors, osteoporosis indicators and vitamin $D$ deficiency of patients among different groups. Compared with those in the CKD I-II stage group, IL-6, CRP, TNF- $\alpha$, serum phosphate, serum sodium, serum potassium and BUN of the patients in the other two groups were significantly increased, but serum calcium, BMD and 25(OH)D were significantly decreased. IL-6, CRP, TNF- $\alpha$, serum phosphate, serum sodium, serum potassium and BUN in the CKD V stage group were significantly higher than those in the CKD III-IV stage group, but serum calcium, BMD and $25(\mathrm{OH}) \mathrm{D}$ were lower than those in the CKD III-IV stage group, which showed statistically significant difference $(\mathrm{P}<0.05)$ (Table II).

Comparison of $\mathrm{Cr}$ between normal and osteoporosis group. Patients were divided into two groups: normal and osteoporosis group on the basis of BMD. It was found that $\mathrm{Cr}$ content of patients with osteoporosis was noticeably higher than that in normal group, which showed a statistically significant difference $(\mathrm{P}<0.05)$ (Fig. 1).

Comparison of $\mathrm{Cr}$ content between groups with normal and abnormal CRP. According to the comparison between the two groups of patients, it was suggested that the $\mathrm{Cr}$ content in the group with abnormal CRP was significantly higher than that in the normal group $(\mathrm{P}<0.05)$ (Fig. 2). 
Table II. Comparison of inflammatory factors, osteoporosis indicators and vitamin D of patients among different groups.

\begin{tabular}{|c|c|c|c|}
\hline Index & CKD I-II stage & CKD III-IV stage & CKD V stage \\
\hline IL-6 (pg/ml) & $99.2 \pm 9.3$ & $125.3 \pm 10.3^{\mathrm{a}}$ & $189.2 \pm 10.7^{\mathrm{a}, \mathrm{b}}$ \\
\hline $\mathrm{CRP}(\mu \mathrm{g} / \mathrm{ml})$ & $2.9 \pm 0.2$ & $6.4 \pm 0.6^{\mathrm{a}}$ & $20.3 \pm 2.0^{\mathrm{a}, \mathrm{b}}$ \\
\hline TNF- $\alpha(n g / m l)$ & $1.22 \pm 0.12$ & $1.79 \pm 0.18^{a}$ & $2.23 \pm 0.23^{\mathrm{a}, \mathrm{b}}$ \\
\hline Serum calcium (mmol/l) & $2.2 \pm 0.2$ & $2.0 \pm 0.2^{\mathrm{a}}$ & $1.5 \pm 0.2^{\mathrm{a}, \mathrm{b}}$ \\
\hline Serum phosphate (mmol/l) & $1.3 \pm 0.1$ & $1.6 \pm 0.1^{\mathrm{a}}$ & $2.0 \pm 0.2^{\mathrm{a}, \mathrm{b}}$ \\
\hline BMD & $0.923 \pm 0.086$ & $0.823 \pm 0.098^{\mathrm{a}}$ & $0.723 \pm 0.067^{\mathrm{a}, \mathrm{b}}$ \\
\hline 25(OH)D (ng/ml) & $20.5 \pm 2.3$ & $14.9 \pm 1.7^{\mathrm{a}}$ & $6.3 \pm 0.8^{\mathrm{a}, \mathrm{b}}$ \\
\hline Serum sodium (mmol/l) & $134.43 \pm 11.56$ & $146.67 \pm 14.09^{\mathrm{a}}$ & $152.09 \pm 15.21^{\mathrm{a}, \mathrm{b}}$ \\
\hline Serum potassium $(\mathrm{mmol} / \mathrm{l})$ & $3.86 \pm 0.45$ & $4.32 \pm 0.39^{\mathrm{a}}$ & $4.78 \pm 0.49^{\mathrm{a}, \mathrm{b}}$ \\
\hline BUN (mml/l) & $13.67 \pm 1.65$ & $14.87 \pm 1.98^{\mathrm{a}}$ & $16.02 \pm 1.99^{\mathrm{a}, \mathrm{b}}$ \\
\hline
\end{tabular}

${ }^{\mathrm{a}} \mathrm{P}<0.05$, compared with CKD I-II stage group; ${ }^{\mathrm{P}} \mathrm{P}<0.05$, compared with CKD III-IV stage group. CKD, chronic kidney disease; IL-6, interleukin-6; CRP, C-reactive protein; TNF- $\alpha$, tumor necrosis factor- $\alpha$; BMD, bone mineral density; BUN, blood urea nitrogen.

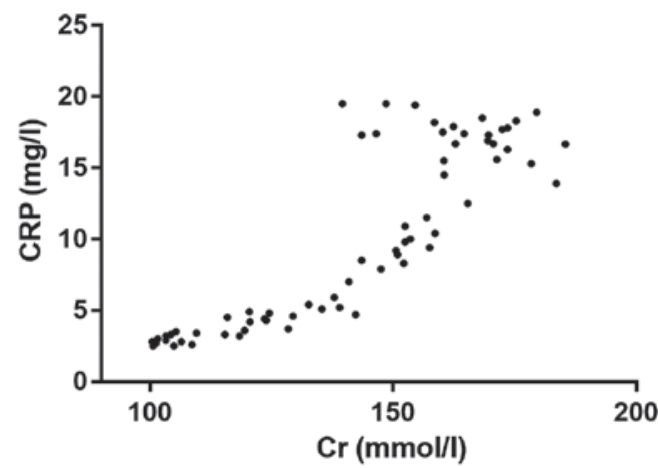

Figure 3. Correlation analysis of $\mathrm{Cr}$ and CRP. Cr, creatinine; CRP, C-reactive protein.

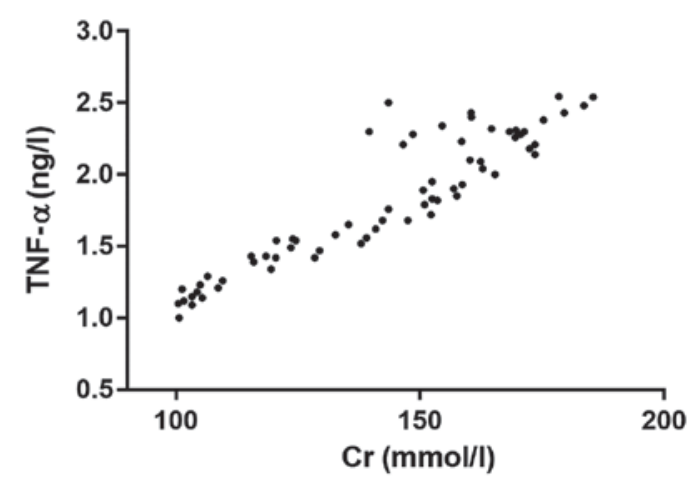

Figure 4. Analysis of the relationship between $\mathrm{Cr}$ and TNF- $\alpha$. Cr, creatinine; TNF- $\alpha$, tumor necrosis factor- $\alpha$.

Correlation analysis of $\mathrm{Cr}$ and $C R P$. Through the correlation analysis, it was found that there was a positive correlation between $\mathrm{Cr}$ and CRP $(\mathrm{r}=0.6961, \mathrm{P}<0.001)$. Thus, with the increase of $\mathrm{Cr}$ level, the content of CRP was higher (Fig. 3).

Analysis of the relationship between $C r$ and TNF- $\alpha$. The correlation analysis showed that there was a positive correlation between $\mathrm{Cr}$ and TNF- $\alpha(r=0.8969, \mathrm{P}<0.001)$, which meant

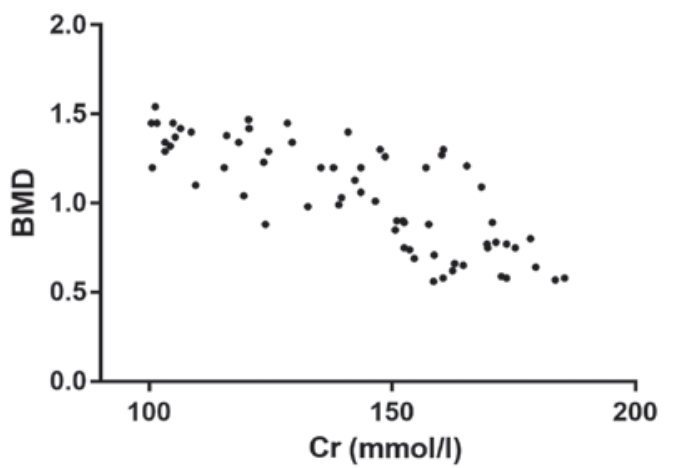

Figure 5. Correlation analysis of $\mathrm{Cr}$ and BMD. Cr, creatinine; BMD, bone mineral density.

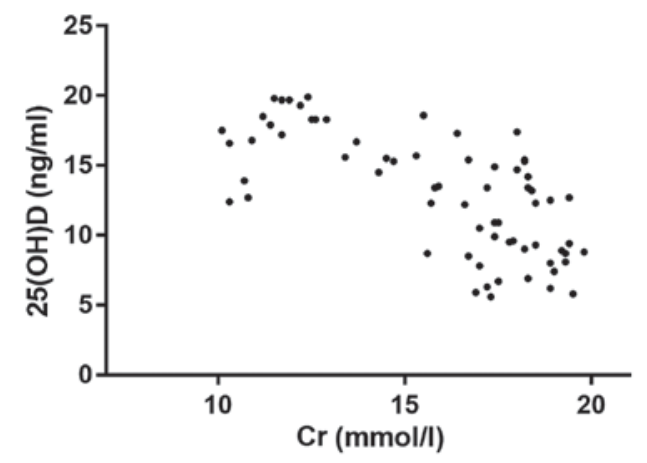

Figure 6. Correlation analysis of $\mathrm{Cr}$ and $25(\mathrm{OH}) \mathrm{D} . \mathrm{Cr}$, creatinine.

that with the increase of $\mathrm{Cr}$ level in the body, the content of TNF- $\alpha$ in vivo was higher (Fig. 4).

Correlation analysis of $\mathrm{Cr}$ and BMD. The correlation analysis showed that there was a negative correlation between $\mathrm{Cr}$ and BMD $(r=0.5472, \mathrm{P}<0.001)$. This meant that with the increase of $\mathrm{Cr}$ level, BMD in vivo was lower (Fig. 5).

Analysis of the correlation between $\mathrm{Cr}$ and $25(\mathrm{OH}) \mathrm{D}$. Through the correlation analysis, it was found that there was a negative 
correlation between $\mathrm{Cr}$ and 25(OH)D $(\mathrm{r}=0.4733, \mathrm{P}<0.001)$. In other words, with the increase of $\mathrm{Cr}$ level, 25(OH)D was lower (Fig. 6).

\section{Discussion}

CKD has a high morbidity rate in clinical practice and causes great inconvenience to patient life and work (11). It leads to many complications including inflammatory infection, osteoporosis and vitamin D deficiency $(12,13)$. To cure and prevent CKD effectively, in-depth studies of the relation of CKD with inflammatory factors, osteoporosis and vitamin D deficiency should be conducted, providing more therapy targets for CKD.

Studies have shown that patients with CKD will suffer from various inflammations, of which the pathogenic factors are mainly renal disease and infection immunodeficiency. Inflammatory infection is not caused by bacteria or viruses, but by higher concentration of IL- 6 released by T lymphocytes and increased expression levels of CRP and TNF- $\alpha$ after the antigen stimulation in CKD patients $(14,15)$. Continuous accumulation of these inflammatory factors produces physiological damage to kidneys and in turn leads to microinflammation in the kidneys, which causes the increased content of inflammation such as IL-6 (16-18). This study showed that there are correlations between the severity of renal inflammation and inflammatory factors including IL-6, TNF- $\alpha$ and CRP. The more severe the disease is, the higher the content of the above inflammatory factors is, which indicates that the severity of CKD is positively correlated with inflammation.

Abnormalities of serum phosphate and serum calcium are detected in patients with CKD, in which the content of serum phosphate is continuously elevated, and that of serum calcium is continuously decreased with the aggravation of the disease. This is considered to be related to metabolic acidosis clinically. Acidosis will destroy homeostasis of serum phosphate, hinder the active transport of small intestinal mucosa and cause passive diffusion of phosphate and abnormal transfer of internal loading of phosphorus. The significant decrease in content of serum calcium in patients with CKD is believed clinically to be associated with elevation of serum phosphate, abnormal arginine intake of calcium and vitamin D deficiency. As an important indicator of bone metabolism in patients, the marked reduction of BMD indicates the reduction of bone mass and high possibility of bone fracture and osteoporosis $(19,20)$. The present study showed that with the deterioration of CKD, the value of BMD is decreased significantly, indicating that patients' osteoporosis is more severe with the worsening of the disease condition. Related research has shown that too high content of serum phosphate will lead to over release of inflammatory factors in patients. In addition, serum phosphate stimulates monocyte and macrophage to release massive inflammatory factors and activates the nuclear factor $\kappa \mathrm{B}(\mathrm{NF}-\kappa \mathrm{B})$ signal pathway, leading to increased content of TNF- $\alpha$. It is speculated that there may be a relation of BMD and IL-6 with the above mechanism.

Vitamin D deficiency is mainly evaluated through the detection of $25(\mathrm{OH}) \mathrm{D}$ that in vivo is combined with the corresponding receptor so as to form interaction between serum phosphate and serum calcium. Vitamin D deficiency is very common in patients with $C K D$, and clinical studies have found that vitamin $\mathrm{D}$ deficiency has become an important risk factor for CKD. In this study, the inflammation degree in CKD was found to be negatively correlated with $25(\mathrm{OH}) \mathrm{D}$, and as the condition became more severe, the content of this factor was lower, which is similar to findings of previous clinical studies (21). Hence, diagnosis, treatment and prevention of CKD can be conducted by measuring the content of this factor.

In summary, the severity of CKD in patients is correlated with inflammatory factors, osteoporosis and vitamin D deficiency. In addition, more serious disease condition causes the release of more inflammatory factors, higher content of serum phosphate, lower content of serum calcium and more severe vitamin D deficiency as well as osteoporosis.

\section{Acknowledgements}

Not applicable.

\section{Funding}

No funding was received.

\section{Availability of data and materials}

The datasets used and/or analyzed during the current study are available from the corresponding author on reasonable request.

\section{Authors' contributions}

CL was responsible for the data analyses and wrote the manuscript. CL and HL collected the clinical and laboratory information. Both authors read and approved the final manuscript.

\section{Ethics approval and consent to participate}

The study was approved by the Ethics Committee of the Union Hospital (Wuhan, China) and informed consents were signed by the patients or the guardians.

\section{Patient consent for publication}

Not applicable.

\section{Competing interests}

The authors declare that they have no competing interests.

\section{References}

1. Chen J, Gu D, Chen CS, Wu X, Hamm LL, Muntner P, Batuman V, Lee CH, Whelton PK and He J: Association between the metabolic syndrome and chronic kidney disease in Chinese adults. Nephrol Dial Transplant 22: 1100-1106, 2007.

2. Cruz MC, Andrade C, Urrutia M, Draibe S, Nogueira-Martins LA and Sesso Rde C: Quality of life in patients with chronic kidney disease. Clinics (Sao Paulo) 66: 991-995, 2011.

3. Jepson RE: Current understanding of the pathogenesis of progressive chronic kidney disease in cats. Vet Clin North Am Small Anim Pract 46: 1015-1048, 2016.

4. Rabbani N and Thornalley PJ: Advanced glycation end products in the pathogenesis of chronic kidney disease. Kidney Int 93: 803-813, 2018. 
5. Arnold R, Issar T, Krishnan AV and Pussell BA: Neurological complications in chronic kidney disease. JRSM Cardiovasc Dis 5: 2048004016677687, 2016.

6. Huan L, Yuezhong L, Chao W and HaiTao T: The urine albumin-to-creatinine ratio is a reliable indicator for evaluating complications of chronic kidney disease and progression in $\operatorname{Ig} \mathrm{A}$ nephropathy in China. Clinics (Sao Paulo) 71: 243-250, 2016.

7. Lips P, Goldsmith D and de Jongh R: Vitamin D and osteoporosis in chronic kidney disease. J Nephrol 30: 671-675, 2017.

8. Shigematsu T, Muraoka R, Sugimoto T and Nishizawa Y: Risedronate therapy in patients with mild-to-moderate chronic kidney disease with osteoporosis: Post-hoc analysis of data from the risedronate phase III clinical trials. BMC Nephrol 18: 66, 2017.

9. Marciniak C, Gabet J, Lee J, Ma M, Brander K and Wysocki N: Osteoporosis in adults with cerebral palsy: Feasibility of DXA screening and risk factors for low bone density. Osteoporos Int 27: 1477-1484, 2016.

10. Ward C, Contino K, Patel A, Mbei EE, Roy S, Hunter K and Gandhi S: The association of serum 25-Hydroxyvitamin D status in patients with osteoarthritis in the primary care office. N Am J Med Sci 8: 47-55, 2016

11. Pongpirul W, Pongpirul K, Ananworanich J, Klinbuayaem V, Avihingsanon A and Prasithsirikul W: Chronic kidney disease incidence and survival of Thai HIV-infected patients. AIDS 32: 393-398, 2018

12. Michishita R, Matsuda T, Kawakami S, Tanaka S, Kiyonaga A, Tanaka H, Morito N and Higaki Y: The association between changes in lifestyle behaviors and the incidence of chronic kidney disease (CKD) in middle-aged and older men. J Epidemiol 27 389-397, 2017.

13. Kochi M, Kohagura K, Shiohira Y, Iseki K and Ohya Y: Chronic kidney disease, inflammation, and cardiovascular disease risk in rheumatoid arthritis. J Cardiol 71: 277-283, 2018.
14. Li ZY, Zheng Y, Chen Y, Pan M, Zheng SB, Huang W, Zhou ZH and Ye HY: Brazilin ameliorates diabetic nephropathy and inflammation in db/db mice. Inflammation 40: 1365-1374, 2017.

15. Batchu SN, Hughson A, Gerloff J, Fowell DJ and Korshunov VA Role of Axl in early kidney inflammation and progression of salt-dependent hypertension. Hypertension 62: 302-309, 2013.

16. Garcia-Bello JA, Gómez-Díaz RA, Contreras-Rodríguez A, Talavera JO, Mondragón-González R, Sanchez-Barbosa L, Diaz-Flores M, Valladares-Salgado A, Gallardo JM, Aguilar-Kitsu A, et al: Carotid intima media thickness, oxidative stress, and inflammation in children with chronic kidney disease. Pediatr Nephrol 29: 273-281, 2014.

17. Lim GB: Arrhythmias: IL-6 and risk of atrial fibrillation in chronic kidney disease. Nat Rev Cardiol 13: 183, 2016.

18. Xun C and Zhao Y: Potential role of soluble TNF- $\alpha$ receptors in diagnosis of patients with chronic kidney disease. Ann Clin Lab Sci 47: 310-314, 2017.

19. Peltonen S, Biancari F, Lindgren L, Mäkisalo H, Honkanen E and Lepäntalo M: Outcome of infrainguinal bypass surgery for critical leg ischaemia in patients with chronic renal failure. Eur J Vasc Endovasc Surg 15: 122-127, 1998.

20. Kumar S, Mavuduru RS and Sharma V: Pan-ureteric transitional cell carcinoma in a patient of autosomal dominant polycystic kidney disease with chronic renal failure. NDT Plus 2: 76-77, 2009.

21. Levin A, Le Barbier M, Er L, Andress D, Sigrist MK and Djurdjev O: Incident isolated $1,25(\mathrm{OH})(2) \mathrm{D}(3)$ deficiency is more common than $25(\mathrm{OH}) \mathrm{D}$ deficiency in CKD. J Nephrol 25: 204-210, 2012.

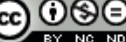

$$
\begin{aligned}
& \text { This work is licensed under a Creative Commons } \\
& \text { Attribution-NonCommercial-NoDerivatives } 4.0 \\
& \text { International (CC BY-NC-ND 4.0) License. }
\end{aligned}
$$

